\title{
INTERACTION OF PHILOSOPHY AND NATURAL SCIENCES IN BYZANTINE EMPIRE
}

The aim of this paper is an analysis of the interaction of philosophy and natural sciences in Byzantine Empire. The cornerstone for this

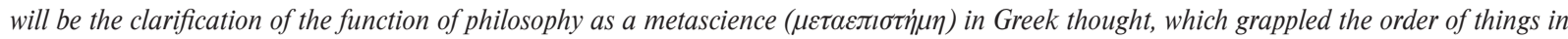
its functional unity of macroscopic and microscopic observation of the world. This macroscopic observation was never at odds with microscopic

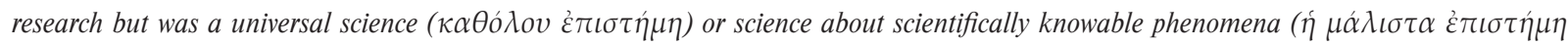
$\tau о \tilde{v} \mu \alpha \dot{\lambda} \iota \sigma \tau \alpha \dot{\varepsilon} \pi \iota \sigma \tau \eta \tau \sigma \tilde{v})$, that is, philosophy. Despite philosophy being an activity closely linked to natural sciences, it is not a science in itself, even though it is often mistaken for such as a term. Philosophy as knowledge, or a function that leads to knowledge, is called science

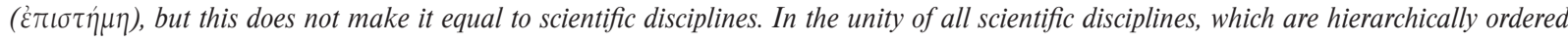
into a pyramid, philosophy always stands on top, it being a science about scientifically knowable phenomena. Out of all the scientific disciplines, philosophy is the one that leads to knowledge of first beginnings and causes. It is a general observation of reality, which secures the unity of

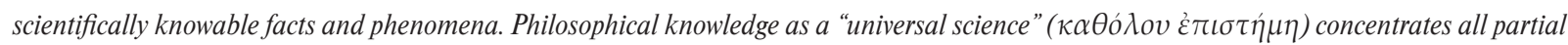
findings into a unified whole. Philosophy is continually attempting to reach a global understanding, while science focuses on a microscopic observation of a specific part of the system.

Keywords: natural sciences, philosophy, metascience, knowledge, Byzantine Empire

\section{Introduction}

In the present, when natural sciences hold a dominant position and the newest technologies are in the center of attention, there is much talk about the purpose of philosophy and its place in the structure of scientific disciplines. Equally common are discussions about whether philosophy belongs to faculties of natural sciences, or even to universities with technical or economic focus. Opinions on the character of scientific research significantly influence the forming of opinions on philosophy. This paper, therefore, aims to contemplate the current character of science on the basis of interaction of philosophy and natural sciences in the Byzantine Empire and thus define the relation of science and philosophy. It also pays attention to several influential Byzantine figures, who furthered both natural sciences and philosophy. Building on the historical analysis of the understanding of the term philosophy, which was first introduced by Pythagoras, calling himself a philosopher [1], the paper also outlines the understanding of philosophy in the structure of scientific disciplines.
Relationship of philosophy and natural sciences has already been discussed at length by many authors, who, despite not reaching a satisfactory and definitive answer to the issue at hand, have produced many interesting observations on the function of philosophy within the system of scientific disciplines [2], while others have tried to approach this topic from a historical perspective [3]. An original explanation of position of philosophy in the structure of scientific disciplines was proposed by Nikos Matsoukas, who also states that "due to the influence of what is primarily Anglo-Saxon and American way of thought, there is no lack of those who easily accept the opinion that every part of specialized science replaced the function of philosophy. From this point of view, not only is there no place for philosophy in the structure of scientific disciplines anymore, but even in case it does accompany and cooperate with scientific disciplines, its function is considered parasitic. Others are trying to very narrowly present philosophy as a specialized scientific discipline, obliged to adjust itself to the purely empirical character of scientific inquiry" [4].

Differing standpoints and interpretations cause misunderstandings and often lead to disagreements between supporters of philosophy and supporters of natural sciences.

\footnotetext{
* Jan Zozulak

Department of Philosophy, Faculty of Arts, Constantine the Philosopher University, Nitra, Slovakia

E-mail: jzozulak@ukf.sk
} 
What is the meaning of the conflict between philosophy and natural sciences? The answer to this question will be sought in Byzantine culture, which continued the tradition of antiquity, where a unified whole of scientifically knowable facts existed and, therefore, a strong unity of scientific knowledge was present. In this unity, philosophy still appeared, so, despite it being different from individual scientific disciplines of the era, it was often mistaken for science as a term. This is understandable because philosophy demands the leading position in the unity of scientific knowledge. From the stated, it is evident that the exploration of philosophy's position in the system of knowledge as a whole, on the basis of a more acute analysis of the relationship of philosophy and individual scientific disciplines, appears as a highly topical theme.

\section{Ancient understanding of philosophy}

Philosophy started being used as a metascience ( $\mu \varepsilon \tau \alpha \varepsilon \pi ı \sigma \tau \dot{\eta} \mu \eta)$ as early as in the sixth century BC in Asia Minor and southern Italia, that is, in Greek colonies, and "this is true regardless of the term philosophy being, in some cases, synonymous with the term science, or later, in Byzantium, with terms theology, asceticism, knowledge of God or Divine illumination" [5].

The main attribute of ancient philosophy is the search for truth, that is, methodical approach to the contents of all kinds of observation. From this perspective, philosophy is an attempt of man to answer the question of being, outer world and inner self through reasoning. The simplest definition of philosophy is that of a universal science, the goal of which is the systematization of human knowledge and attempts at creating a theory of world and theory of life [6]. The goal of different philosophical movements was more or less the same; the main difference dwelt mostly in the means to achieve this end.

Defining philosophy is not simple, as "every philosophical system brings with it its own definition" [7]. Despite this, various definitions of philosophy resonate in both early and later Byzantine texts, repeating - with small variations - the six classical definitions, systematized by Platonic commentators, e.g., Ammonius, David, and Elias, attributed to Pythagoras, Plato, and Aristotle [8]. According to these definitions, philosophy is:

1. knowledge of being as such (attributed to Pythagoras);

2. assimilation with God as much as humanly possible (Plato, Theaetetus);

3. knowledge of divine and human things (Pythagoras);

4. preparation for death (Plato, Phaedo);

5. art of the arts and science of the sciences (Aristotle, Metaphysics)

6. love of wisdom (Pythagoras).

In writing, these definitions were typically presented together with the division of philosophy in general into theoretical and practical philosophy. Theoretical part deals with knowledge and incorporates physics (pertaining to material things), mathematics (geometry, arithmetic, astronomy, and harmonics), and theology (immaterial beings: God, angels, souls). Practical part deals with virtues and incorporates ethics, economics, and politics.

\section{Is philosophy a science?}

An unavoidable prerequisite for metascientific, macroscopic, systematical and universal evaluation of any fact is the scientific observation of a part of scientifically knowable facts. And so, despite being an activity closely linked to natural sciences, philosophy is not a science in itself, even though it is often mistaken for such as a term [9]. Philosophy as knowledge, or a function that leads to knowledge, is called science ( $\dot{\pi} \pi \sigma \tau \eta \dot{\mu \eta})$, but this does not make it equal to ancient scientific disciplines. In the unity of all scientific disciplines, which are hierarchically structured into a pyramid, philosophy always stands on top, being a "science about scientifically knowable phenomena" (or, more literally, knowledge of that, what is most knowable) ( $\eta \mu \alpha \dot{\alpha} \lambda\llcorner\tau \tau \alpha$

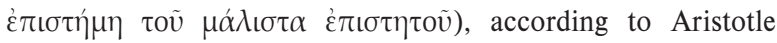
[10]. From his texts, it is clear that, out of all the scientific disciplines, philosophy is the one that leads to knowledge of the first principles and causes. It is a general observation of reality, which secures the indivisible unity of scientifically knowable facts and phenomena. Philosophical knowledge as

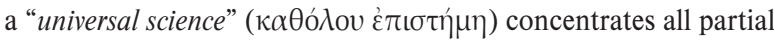
findings into a unified whole. The wise man, or philosopher, is a person who knows the first causes, through which one sees the unified whole of the scientifically knowable phenomena. The function of this knowledge unifies all parts of the scientifically knowable phenomena - and, naturally, even partial findings become understandable - and on the other hand, it is theoretical knowledge, serving as a means for the cultivation of man.

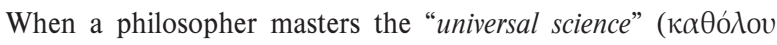
$\dot{\varepsilon} \pi \iota \tau \eta \dot{\eta} \mu)$, it does not mean that he has an encyclopedic education. His cognitive experience is an ability through which he can see the first unification of parts into a whole of scientifically knowable phenomena, can connect and search for links between all the parts of knowledge and can develop his education using spiritual cultivation [11].

Philosophy is continually attempting to reach a global understanding, while science focuses on microscopic observation of a specific part of the system. Despite this, philosophy as a metascience critically and scientifically proposes the principles of understanding of world, humanity, society, and reality in its entirety. Every philosopher, independently on fundamental principles of interpretation of world and life, is interested in knowledge of all areas of scientifically knowable phenomena and tries to collect and systematize them. Aristotle, in this case, is a typical example of such collectional work with the goal of ordering all the findings, with philosophy holding the prominent 
place at the top of this pyramidal hierarchy. The same continues in Byzantine Empire, where, in explaining of Christian doctrines, educated thinkers order theological findings within the system of all scientifically knowable phenomena in such a way that theology stands on the top of the scientific disciplines, thus replacing philosophy. A characteristic example of this is John of Damascus, as is evident from his third book of the trilogy The Fount of Knowledge [12], titled An Exact Exposition of the Orthodox Faith [13], in which he, in accordance with the popular notion of the era, concisely and accurately explains the content of Christian faith in one hundred chapters, using the basic scientific findings of astronomy, geology, psychology, physics, and other sciences. He even uses the language of mathematics for expressing of dogmatic truths [14]. In his reasoning, there is a clear connection between science, philosophy and theology, despite the dominant position held by orthodox faith.

This influential Byzantine thinker, poet, and artist also offers an answer to the question of the method of philosophical inquiry and what exactly is understood as philosophy: Philosophy is the art of arts and the science of sciences. This is because philosophy is the principle of every art, since through it every art and science has been invented. Now, according to some, art is what errs in some people and science what errs in no one, whereas philosophy alone does not err. According to others, art is that which is done with the hands, whereas science is any art that is practiced by the reason, such as grammar, rhetoric, and the like" [15]

The first book John's trilogy, titled Dialectics or the Philosophical Chapters [16], in which he reflects on the ancient philosophical thought of the four pre-Christian centuries and Christian thought of the first eight centuries can be labeled an original work on the history of philosophy [17].

\section{Unity of philosophy and natural sciences in Byzantine culture}

One of the great Byzantine thinkers was an outstanding philosopher, theologian and historian Photios the Great (820891), who contributed to the blooming of Greek writing [18]. He possessed an unusual ability to carry out textual analysis. He dealt with various topics and was able to, in only a few words, capture the essence of the issue at hand. His profound knowledge manifested itself in his evaluation of various questions. Basil Tatakis even writes about him: "As an intellectual, he is the only one in Byzantium who can be compared to Aristotle" [19]. On the basis of Photios' excellent knowledge, we can assume that education in the Byzantine Empire was at a very high level during that period. At this time, in addition to philosophy, all of the ancient sciences began to be further developed. An example of this development is the teacher of Photios, philosopher and scientist Leo, the Philosopher, or the Mathematician (c. 790-869), who was well known for his exemplary skills in the fields of philosophy, music, mathematics, astronomy, mechanics, and physics. He was so renowned for his wisdom that caliph Al-Ma'mun (813-833) invited him to teach in his palace and promised him fame and fortune. He concurrently wrote a letter to the Emperor Theophilos and offered him a large amount of gold, but the Emperor rejected this proposition, awarded Leo with salary and conferred a school on him.

One of the most prominent figures of the eleventh century was the Christian humanist, John Mauropous (end of 10th century - after 1075), who differed from his contemporaries by his free thinking and original ability to formulate his thoughts. After finishing studies of philosophy, rhetorics and law, he became a practicing teacher and founded a private school in his birth house, which soon gained very positive reputation and attracted students from the entire Byzantine Empire [20].

Among John Mauropous' students was a profoundly talented and versatile author Michael Psellos (1018-1078), whose rich literary output clearly reflects the state of contemporary Byzantine philosophy, dialectics, rhetoric, grammar, geometry, arithmetic, ethics, psychology, biology, botany, zoology and other sciences. This polyhistor had a unique gift to encompass in his ideas the entire Byzantine cultural tradition and with its synthesis contributed to the development of Byzantine science and philosophy. He studied Aristotle, Plato, Plotinus, Porphyry, Iamblichus and Proclus and was rightfully given the title Chief

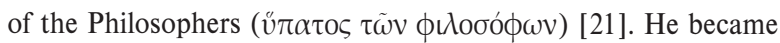
renowned for renewal of Platonic and Neoplatonic studies - some of the influential Neoplatonic work was preserved solely in his commentaries. Michael Psellos was a scientist, philosopher, and a rhetorician [22], under whom, for the admiration of his knowledge, many scholars came to study. $\mathrm{He}$ was also a theologian, who was fully aware of the significance of the dual methodology in Byzantine works, therefore "charismatic theology was his life; scientific observation of individual parts of knowable phenomena something separate; and philosophy a meaningful observation of every knowledge" [23].

Despite the complicated political events, which negatively influenced Byzantine educational institutions in $13^{\text {th }}-15^{\text {th }}$ centuries, there were multiple capable scholars who constructively reacted to various topics, dealt with art and attempted to arouse interest in natural sciences and philosophy. Many intellectuals fled to Nicaea, where the Laskaris dynasty, which supported education, had settled, and continued their activities there. The most significant philosopher of this period was Nikephoros Blemmydes (1197-1272), who was also an excellent pedagogue. Emperor Michael VIII Palaiologos [24] entrusted him with managing the imperial school in Constantinople. Among his prominent works are Epitome logica [25] and Epitome physica [26], in which he displayed a good knowledge of Aristotle, Simplicius, Philoponus, and others. These texts are, in essence, didactic handbooks for students with brief descriptions, the structure of which is founded on systematic work of Michael Psellos. 
Among Nikephoros' foremost disciples were the historian George Akropolites (1217-1282) and philosopher Theodore II Laskaris (1233-1258), who showed great interest in Greek education. He took up philosophy, poetry, and theology and later became Nicaean Emperor. He was faithful to the tradition of Byzantine thinkers, utilizing the dual methodology, also seen in works of his predecessors, according to which philosophy is the highest good for education and natural sciences. In addition to this, he boasted excellent knowledge of physics and mathematics, a proof that philosophy, theology, art and natural sciences formed a marvelous unity in Byzantine culture. Natural sciences and mathematics also influenced such significant philosophers as George Pachymeres and Maximos Planoudes.

The philosopher and historian George Pachymeres (12421310) was the greatest polyhistor of his time, showing remarkable knowledge in the fields of physics, mathematics, philosophy, theology, and music. In addition, he knew the works of ancient authors and paraphrased Aristotle, Diophantus, and PseudoDionysius the Areopagite. His text Philosophy ( was preserved in Latin translation as Paraphrasis in universam philosophiam Aristotelis; only a short excerpt was preserved in original. His summary of Aristotelian philosophy did not deal with only logic and physics, but also with mathematics and ethics. Pachymeres is the author of the sole late-Byzantine commentary on Plato, which represents the completion of an unfinished commentary on the dialogue Parmenides by Proclus.

The philologist, mathematician and astronomer, Maximos Planoudes (c. 1255-1305), belongs among the chief scholars of the period. He attempted to elevate education through mathematics and to avert the risk of upcoming fall of the Byzantine Empire. He produced handbooks of grammar, published Ptolemy's Geography and texts of ancient authors with commentaries. His literary activity was not limited to Greek - he also mastered Latin, from which he translated works of Cicero, Macrobius, Augustine, Boethius and Thomas Aquinas. The most important of these is likely Augustine's De trinitate. By means of translation, Planoudes became an intermediary between Eastern and Western world and can be considered the predecessor of the revival of classical Greek studies in the West.

Nikephoros Choumnos (c. 1250-1327), who dedicated himself to natural philosophy, focused primarily on cosmology and psychology, despite having an excellent knowledge of Plato, Aristotle, and Neoplatonic philosophers. In his opinion, ideas or objects do not exist outside of material reality perceptible by senses. People delimit them directly in the perceptible objects themselves. Choumnos' presumptions are not Aristotelian, but theological, as he states that only God exists as self-constituted ( $\alpha \dot{\theta} \theta \dot{\pi} \pi \alpha \propto \kappa \tau о \varsigma)$ and independent on all things sensible and intelligible. This stance was therefore based primarily on Platonic philosophy [27].

Another noteworthy thinker of this period was the polyhistor and forefront humanist Theodore Metochites (1270-1332), who possessed excellent knowledge of mathematics, astronomy, and philosophy. He wrote commentaries on Aristotle's natural philosophy and clarified philosophical opinions of approximately seventy different authors. He attempted to rid astronomy and natural sciences of unscientific approach, magic, fatalism, and superstition.

The fourteenth century - during which notable personalities were active in both Constantinople and Thessaloniki, actively participating in the social and political life of Byzantine Empire - is today considered extremely fruitful. In addition to the development of natural sciences and philosophy, a contact of Eastern and Western cultures took place, causing increased interest of Byzantine philosophers, theologians and politicians in Western thought and theological ideas. Many Byzantine scholars tried to understand Western culture and reacted to many of its questions. This creative philosophical climate decisively influenced later Byzantine thought, which makes this period highly important in the history of philosophy.

\section{Relationship of philosophy and science}

According to Nikos Matsoukas [28], in ancient and Byzantine cultures, almost all scientific disciplines, but primarily mathematics, served as a basis for philosophical thought, which still led to wider and universal goals [29]. At the same time, the philosopher himself ensured the unbreakable unity of cognitive areas of scientifically knowable facts. This means that philosophy brought a functional unity and cohesion to all scientific knowledge on the one hand, and, on the other, explained the world and life as a whole and provided things with sense and meanings. Today, analogical situation is often unthinkable, at least in Anglo-Saxon and American context. Even the individual scientific disciplines are gradually losing their reciprocal unifying bonds and are attaining greater autonomy through fragmentation of the sum of scientifically knowable phenomena into numerous individual fields. This way, over time, many scientific specializations form, leading to additional, more narrow specializing within already specific areas of scientific inquiry. This contemporary state is in no way similar to the image of hierarchical pyramid of scientific disciplines of antiquity, with philosophy on its top.

In the current reality, not only is there an evident absence of this hierarchical unity of scientific disciplines, but also the lack of interpretative function, which would define principles, causes, sense, and meanings within this unity. A hostile stance towards metaphysics is therefore understandable in such context [30],

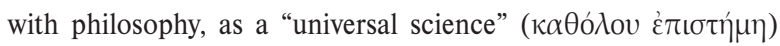
in Aristotelian terms, removed from the structure of scientific disciplines. In the given situation, American spirit, which prevails also in the Western (European) way of thinking, leads to the introduction of the "schizophrenic" shattering of being. Humanity loses the proper relationship with the environment, world, and 
life. It is bound to certain parts of knowledge, which it could know exhaustively, yet would not be able to incorporate them into a whole.

What makes a proper relationship between man and the world - a "macroscopic," or "microscopic" observation of the total reality? Is "awe" or practical need the reason for knowledge of the world and life? These philosophical questions will always stay topical. Such dilemmas were absolutely unknown, even unthinkable to ancient Greek and Byzantine thought. They are, however, typical for the spiritual context of the Western culture, for which such schizophrenic fragmentation is characteristic. Greek thought grappled with the order of things in its functional unity of macroscopic and microscopic observation of the world. This macroscopic observation, which was never at odds

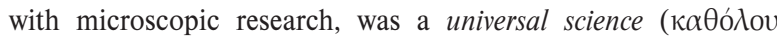
$\dot{\varepsilon} \pi \iota \tau \eta \dot{\mu \eta})$ or science about scientifically knowable phenomena ( $\eta$

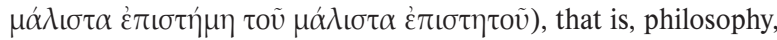
as stated earlier.

\section{Natural and spiritual sciences}

Nikos Matsoukas writes: "Science is an observation of collected and systematically arranged homogeneous findings of a single field of scientifically knowable phenomena through specific methods of work" [31]. The sum of scientifically knowable phenomena is understood here as both the entire natural reality and spiritual wealth or cultural heritage. This means that the unified and comprehensive sum of scientifically knowable phenomena is, in principle, divided into natural and spiritual. Just as there is no doubt that natural scientifically knowable phenomena are something concrete, so are spiritual scientifically knowable phenomena concrete, perceptible and visible. One must not be fooled by certain contemporary unscientific opinions (which sometimes, unfortunately, circulate also in various scientific circles) and presume that the spiritual sum of scientifically knowable phenomena is something hypothetical or made up, even "invisible." These phenomena are the results of humanity's spiritual activity: language, texts, works of art, monuments and so on. In such manner, also scientific disciplines are divided into natural and spiritual, on the basis of the phenomena they deal with. Interesting and detailed views on the division of scientific disciplines are provided by Evangelos Papanoutsos [32], Nikos Matsoukas considers the division of sciences into exact and theoretical to be unreasonable and possibly correct only under the assumption of an appropriate preceding division into natural and spiritual [33]. Exact sciences (usually labeled as natural sciences) have a clear methodology worked out

For the possibility of a minute and scrupulous observation, the sum of scientifically knowable phenomena is divided into many fields, with individual specialized scientific disciplines (e.g., physics, medicine, agriculture) thus being born. Despite this, every specialized scientific discipline is subdivided further and further. This division, proportionally to scientific discoveries and application of findings in practice, can continue or modulate almost indefinitely. The entirety of homogeneous findings resulting from research in a single field of a specialized sum of scientifically knowable phenomena constitutes the contents of a specific specialized scientific discipline. Similarly, also the spiritual sum of scientifically knowable phenomena is subject to the same fragmentation, leading to the creation of individual specialized spiritual disciplines (philological, legal, theological and others). Same division can be observed in individual specialized scientific disciplines, analogically to natural sciences. Here, too, the unity of homogeneous findings resulting from the research in a single area of the spiritual sum of scientifically knowable phenomena constitutes the contents of a concrete specialized scientific discipline. It is, therefore, possible to come to a fundamental and universal conclusion: it is impossible to talk about science without its specific sum of scientifically knowable phenomena.

In the same manner, it would be impossible to talk about science without specific methods of scientific inquiry, which can differ in character on the basis of the utilizing scientific discipline, yet they never lose the basic characteristics of their universal framework (natural or spiritual sum of scientifically knowable phenomena), into which they belong when presenting scientific research. Empirical observation, experiment, utilization of computers - these are a few of the methods necessary in natural sciences. Use of computers leads to the necessity to utilize mathematics, itself a possible member of the natural sciences group. Division of scientific disciplines, in general, is difficult, as every scientist perceives for them a different foundation, be it the object of observation, method, goal or something else entirely. In their categorization, division into natural and spiritual sciences is therefore preferable.

On the other hand, even spiritual scientific disciplines possess methods of inquiry appropriate to the observed sum of scientifically knowable phenomena, such as marking of monuments, texts, sources of all kinds, their comparing, even observation of social phenomena in their creation and so on. One can claim, on the basis of the sum of scientifically knowable phenomena of every scientific discipline and adequate methods of scientific inquiry, that every scientific discipline (both natural and spiritual) has its own theoretical and practical component. Furthermore, after compiling the homogeneous findings in every scientific discipline, their systemization and incorporation into the conceptual apparatus are necessary. This is a theoretical activity. Despite this, it is possible to declare that in natural sciences, practical component is dominant, while in spiritual sciences, theoretical component is more prominent. Clearly, this division does not make any scientific discipline purely theoretical or practical. In any case, it is necessary to stress that spiritual scientific disciplines are also empirical, as they all deal with a specific sum of scientifically knowable phenomena, which 
instructs observation and comparative research. For example, archaeology - which cannot be perceived in any other way than as a spiritual science - holds predominantly empirical background, on which its research must be built. From this point of view, it can be said that psychology (and even depth psychology) is a natural science, while sociology is an empirical spiritual science, since the matters it observes are empirical phenomena of human behavior. The fact that sociology deals primarily with origins of social phenomena has no relevance here: it is a matter of fact that these are phenomena of spiritual life and that their observation by sociology is empirical, and that all spiritual scientific disciplines share this empirical character [34].

\section{The interpretative function of philosophy}

Philosophy, as an interpretative function, holds a significant position in both the structure of scientific disciplines and life [35], the conflict of philosophy and natural sciences can thus be seen as entirely senseless. Philosophy is a universal science; other sciences are specialized. Philosophy has a distinctive autonomy and must be differentiated from individual scientific disciplines. According to Matsoukas, philosophy as a function of spirit has no specific sum of scientifically knowable phenomena, it can perform specific work at first, providing systematic and mental structuring to the homogeneous findings of each scientific discipline (both natural and spiritual) and then, unifying specific with universal, provide things with sense and meaning [36]. Philosophical knowledge, starting from special systemization of scientific findings, progresses towards a universal understanding of world and life and becomes a distinctive type of knowledge, in contrast to concrete knowledge of individual scientific disciplines, which are beneficial even in concrete utilization. Philosophy builds on scientific disciplines and on every observation of the world's features and life on one hand, and, on the other, explains the world and life by forming its universal understanding. In other words, philosophy does not have a concrete sum of scientifically knowable phenomena, nor does it carry out scientific research through specific methods, but rather observes by means of interpretation and proposes meanings which can attain universal dimensions [37].

For a better understanding, Matsoukas provides several examples: Statistical scientific research can provide many empirical findings about the social causes of criminality, but will never lead to the ability to draw conclusions about the position of evil in the world, that is, whether evil has a meaning or is a part of other signs of life. These meanings can be observed only by philosophy, on the basis of observation of phenomena, premises of scientific inquiry and critical thought. On the basis of individual conclusions, philosophy can derive universal meanings. Similarly, historical research of causes of wars and revolutions in specific temporal intervals can suggest much, but for a history expert using only the facts of his research, it will never be easy to talk about goals of historical events, about existence or non-existence of teleological line in history, etc. This task is interpretative and belongs to the competence of philosophy. This, understandably, does not mean that a person dealing with scientific inquiry is not able to carry out an interpretation on the basis of such research or deduce universal and metaphysical dimensions, as the historian A. J. Toynbee did in this specific example. Furthermore, a scientist dealing with natural sciences could never conclude, on the basis of purely empirical facts of individual descriptions of matter, elements and environment, whether there is a universal goal in the universe, special directions of inorganic and organic world, or whether there exists an equality of "rights" in the space of living, especially sapient beings. All of this can be, however, interpreted by philosophical contemplation, which, building upon all empirical facts and critical analysis, comes to a variety of thoughts and of universal inquiry. This interpretative view of philosophy can be held by a researcher in the beginning, before approaching any research. In addition, such an interpretative view and such a theoretical observation of the world and life have always led prominent scientists to revolutionary discoveries [38].

In other words, philosophical contemplation never looks at individual parts, fragmentary elements, "shattered" world, but rather connects all phenomena and all findings about phenomena with organic strands and topical understanding. It does not refuse the specific, but turns towards the universal, or, more accurately, places the specific within the universal. In this manner, a scientist who is also a philosopher unites the facts and perceives them macroscopically, despite "shattering" the sum of scientifically knowable phenomena and researching them microscopically, thus overcoming the static, fragmentary and impersonal elements of the world and life. Furthermore, the totality of reality itself is inexorable towards the lone empirical scientist, as it comprises both the specific and the universal. The specific does never exist in itself. No matter how we look at it, scientists cannot, in the end, divert from an interpretative approach towards their findings. Recently, for example, in the field of biology, evolutionists were divided into two groups: the first considered evolution a random and mechanical development, while the second were certain that there is a "goal" behind its direction. The standpoints of both groups result not from the observed facts, however abundant and perfect they might have been, but were rather an interpretative conclusion. It is at this point where science and philosophy meet; from this point, the philosophical inquiry could depart and shift to universal and metaphysical dimensions [39].

\section{Conclusion}

Philosophy is an interpretative function of the spirit, surmounting the fragmentary, static and impersonal elements of the world and life, and unifying the specific with the 


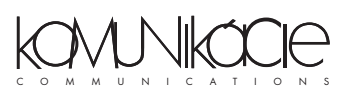

universal while providing sense and meaning to all things and findings in a dynamic and holistic dimension [40]. Philosophy is a metascience ( $\mu \varepsilon \tau \alpha \varepsilon \pi 1 \sigma \tau \eta \dot{\eta} \mu)$, and this function carries with it primarily the invaluable service for systemization of homogeneous findings of every specialized science. Philosophical intellect can focus on research of both natural and spiritual sum of scientifically knowable phenomena more aptly and with a greater observational ability than non-philosophical and uncouth thought. Great inventors and scientists in the field of natural sciences have always had well-developed philosophical sensibilities and "awe" [41].

Philosophy instructs the cultivation of diversity, perhaps even competition of interpretative opinions, but never fanaticism, violence, and cruelty. And it can achieve this to a significant extent when cultivating criticism and dialogue [42]. Moreover, philosophy, as a language of spiritual environment and as a manner of thought, creates a space for the emergence of leading figures, as well as for great discoveries and scientific inventions and moves itself into the awareness of nations.
Ultimately, every person philosophizes, whether willingly or unwillingly, whether consciously or subconsciously. And when one refuses philosophy as worthless and useless, or as a dangerous fancy, he also only philosophizes, becoming a commentator on a certain spiritual phenomenon of life [43]. On the basis of the stated facts, the opinion that philosophy is a matter of academic ground appears incorrect. The conflicts between natural scientists and philosophers are thus, in the same vein, baseless.

\section{Acknowledgment}

This work was supported by the Slovak Research and Development Agency under the contract No. APVV-16-0116.

\section{List of abbreviations}

PG Patrologia cursus completus. Series Graeca. Paris: J.-P. Migne, 1857-1866.

\section{References:}

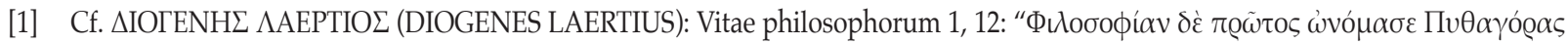

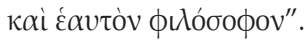

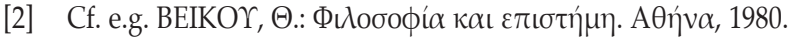

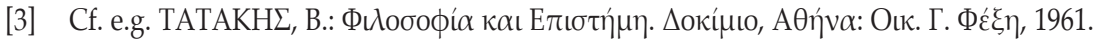

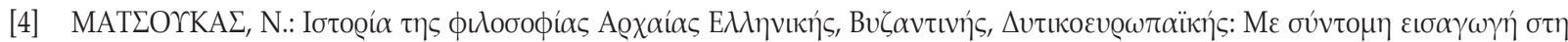

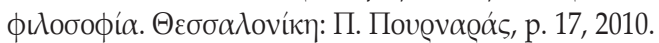

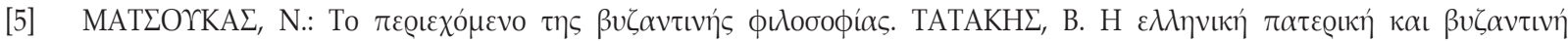

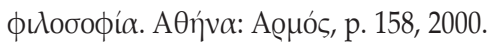

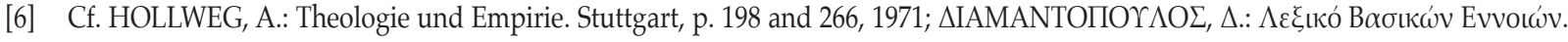

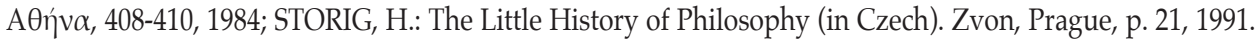

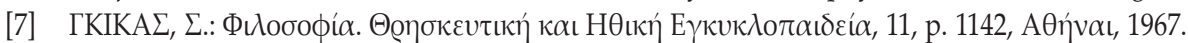

[8] Cf. IERODIAKONOU, K.; ZOGRAFIDIS, G.: Early Byzantine Philosophy. GERSON, L. P. (Ed.). The Cambridge History of Philosophy in Late Antiquity, vol. II. Cambridge University Press, p. 846, 2010.

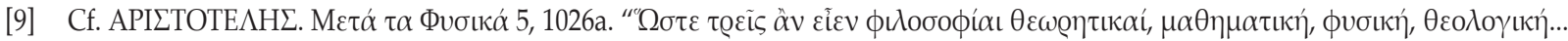

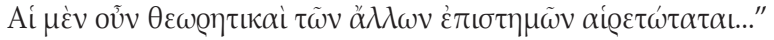

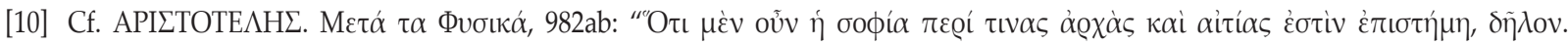

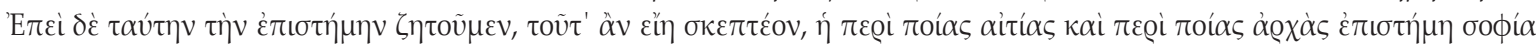

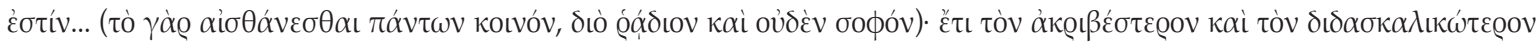

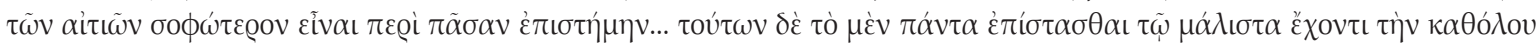

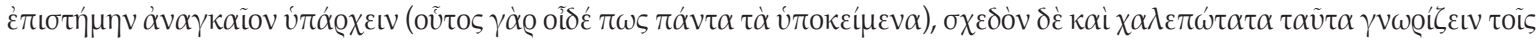

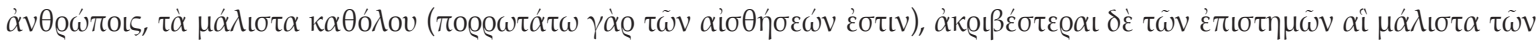

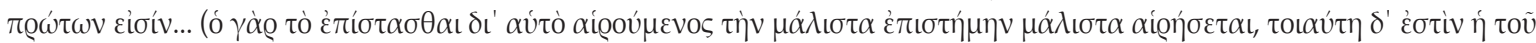

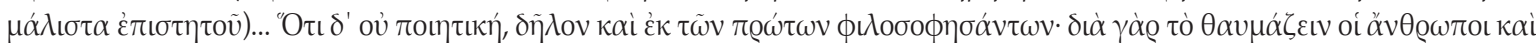

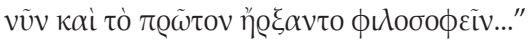

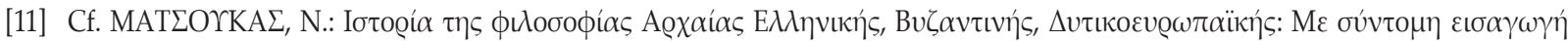

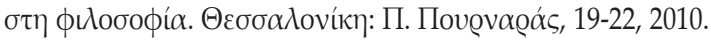

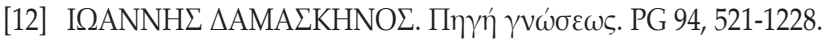

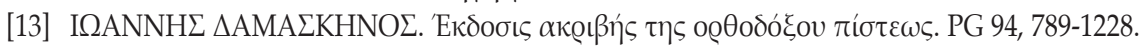




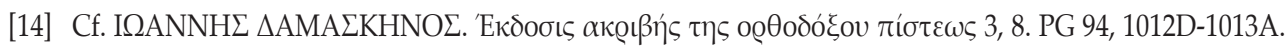

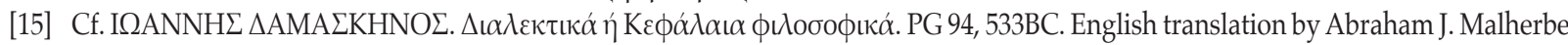

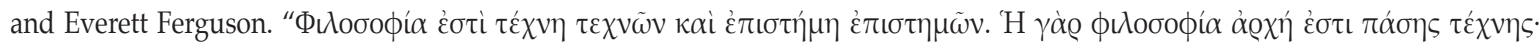

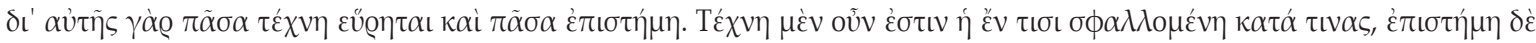

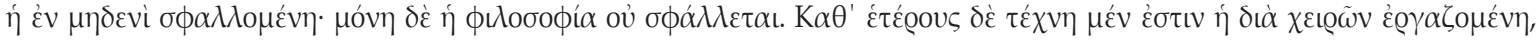

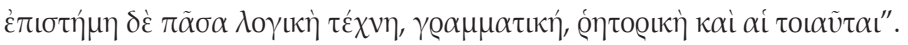

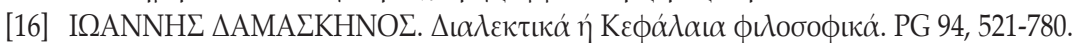

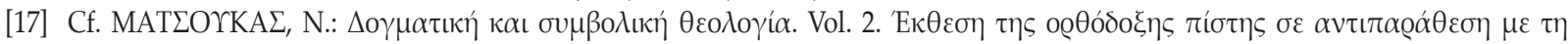

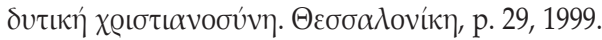

[18] Cf. LAMPROU, S.: East and West in the Work of Photios the Great Patriarch of Constantinople. Constantine's Letters, 9(1), p. 11, 2016.

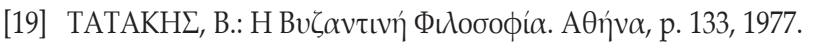

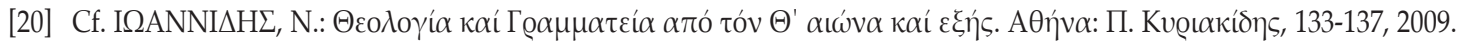

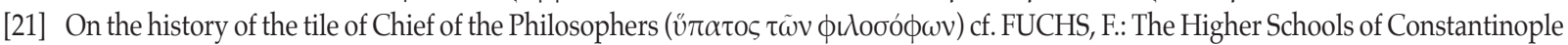
in the Middle Ages (in German). Byzantinische Archiv 8, Leipzig - Berlin, p. 55, 1926.

[22] Cf. PAPAIOANNOU, S.: Michael Psellos: Rhetoric and Authorship in Byzantium. Cambridge, p. 29, 2013.

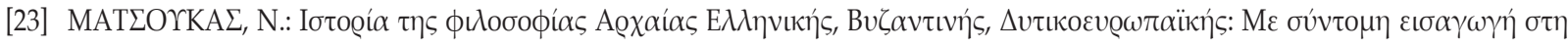

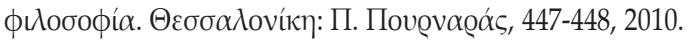

[24] Michael VIII Palaiologos freed Constantinople in 1261, thus starting the period of cultural upswing, known as Byzantine Renaissance.

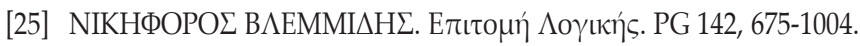

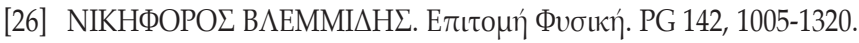

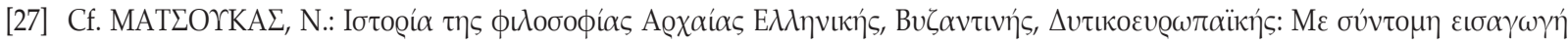

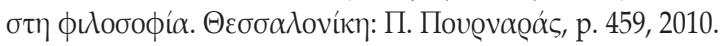

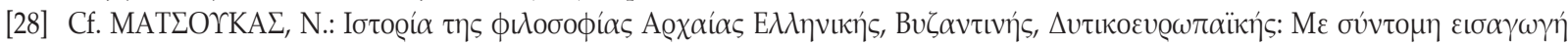

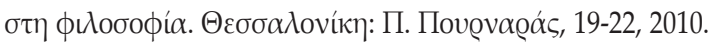

[29] Xenocrates did not let a certain person to study under his lead, because this person did not have the necessary scientific education.

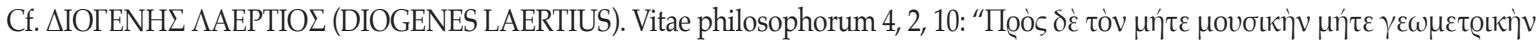

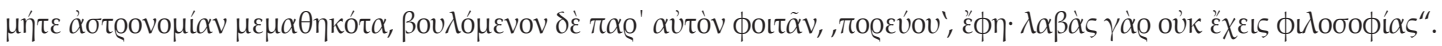

[30] Immanuel Kant writes ironically about metaphysics in the introduction to his Critique of Pure Reason, stating that metaphysics was the queen of all sciences, but now proves despised on all sides, a matron outcast and forsaken. Cf. KANT, I.: Critique of Pure Reason (in German). Hamburg, 5-6, 1956.

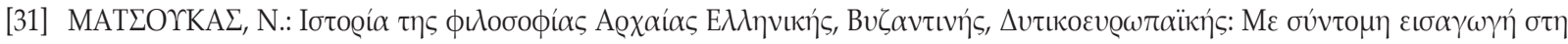

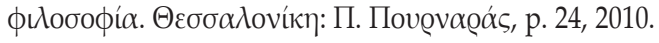

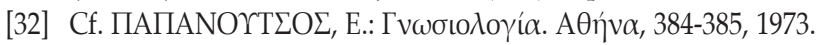

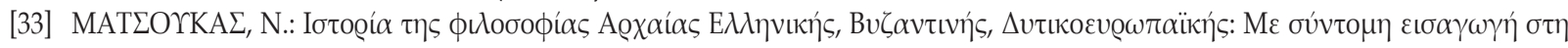

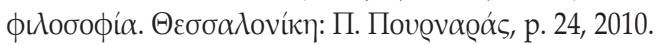

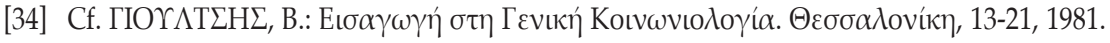

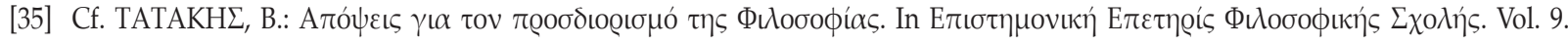

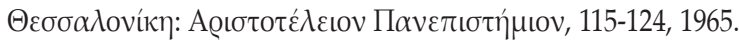

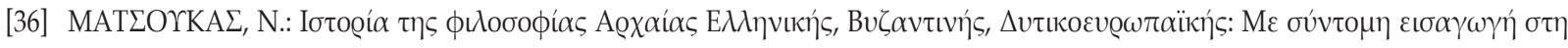

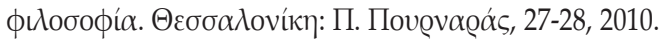

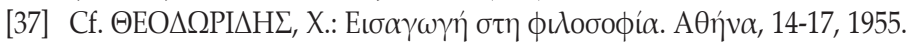

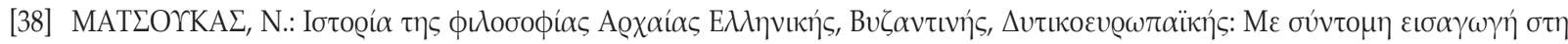

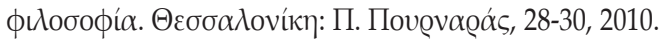

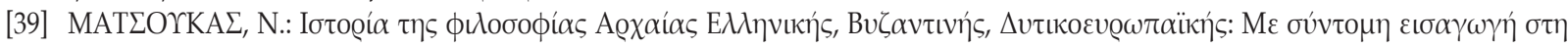

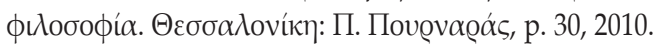

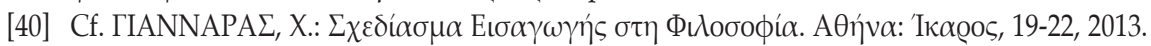

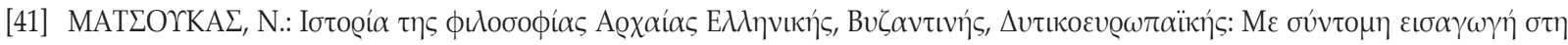

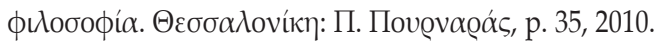

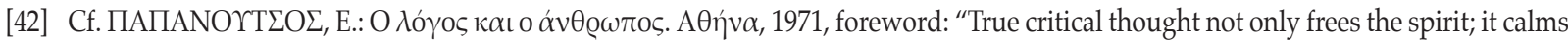
the heart and washes the hands of humanity".

[43] Cf. $\triangle \mathrm{IOTENH} \Lambda \mathrm{AEPTIO}$ (DIOGENES LAERTIUS). Vitae Philosophorum, 6, 2, 64. 